\title{
Commentary
}

\section{Nutrition in Cancer Prevention: An Integrated Approach}

Key words: diet, health policy, health promotion, prevention and control of neoplasms, nutrition policy

\begin{abstract}
There is considerable evidence that the war on cancer is not being won. There is, however, strong evidence that a substantial fraction of cancer can be prevented by using existing nutritional knowledge. In this paper we discuss strategies for reducing cancer incidence by implementing this knowledge. The most obvious route for persuading large numbers to change their diets is by individual counseling in a health-care setting, public education campaigns and interventions at the worksite. However, such health promotion actions have met with only limited success. For efforts to change population diets to be successful, a vital component must include changes in government policies. Examples of the tools that need to be employed are restrictions on advertising and marketing. Effective action will likely require an economic dimension, namely the employment of taxation and subsidies, for instance, by taxing unhealthy food choices and by subsidizing fruit and vegetables.
\end{abstract}

\section{INTRODUCTION}

Several groups of investigators have argued that ostensible advances in cancer treatment are illusory and that the war on cancer is not being won [1]. For instance, Bailar and Gornik [2] concluded that changes in cancer mortality have been due not to improved treatments, but to other causes, and that effective preventative strategies are still lacking. Similarly, Welch et al. [3] concluded that reports of increased five-year survival for cancer patients are not due to therapeutic successes, but rather are artifacts resulting from increased emphasis on early diagnosis.

All this suggests that little real progress has been made in treating cancer and, more important, toward preventing the disease. In the light of what we have come to know about lifestyle and various cancers, this sluggishness represents a lost opportunity. While there is evidence that immutable genetic susceptibilities play a part in cancer, there is also overwhelming evidence that modifiable features of lifestyle and environment, most notably smoking and nutrition, dominate in the disease. In fact, it has been estimated that dietary factors, which will be focused on here, are responsible for at least one third of cancer mortality [4].

This paper, accordingly, considers some obstacles to cancer prevention and reviews the importance of bringing preventative strategies, chiefly dietary ones, to the forefront of our approach to cancer. We build on arguments made previously by Temple and Burkitt [1] that the war being waged on cancer is based on a flawed strategy that seriously underplays cancer's preventable nature. The earlier paper called for a shift away from research into the detailed mechanisms of cancer, towards research into lifestyle's role in the disease.

\section{NUTRITION AND THE PREVENTION OF CANCER}

The reason we are failing to win the war on cancer is not for lack of trying. The cancer treatment front per se is diverse, its armament impressive. The major problem keeping us from winning the war on cancer is the low profile of easily employable, cancer-preventing strategies. This problem stands out when one considers that over the last decade, despite the relatively low priority placed on simple preventative nutrition, knowledge in this area has advanced significantly. Many foods and specific food constituents have been investigated for their potential role in cancer prevention [5,6]. Impressive epidemiological evidence shows, for instance, that a generous intake of whole grains reduces risk of cancer by about one third $[7,8]$ and that a generous intake of fruits and vegetables reduces risk of most types of cancer by 30 to 50 percent [9].

But there are still many gaps in our knowledge. While we have good epidemiological evidence that some foods preventand others cause-cancer, there are only tentative mechanistic explanations. To illustrate, selenium, folate, carotenoids (e.g., $\beta$-carotene and lycopene) and dietary fiber are suspected anticarcinogens found in foods. Research does not clearly indicate how selenium works or in which chemical form it works best

Address correspondence to: Dr. Norman Temple, Centre for Science, Athabasca University, Athabasca AB T9S 3A3 CANADA. E-mail: normant@athabascau.ca

Journal of the American College of Nutrition, Vol. 21, No. 2, 79-83 (2002)

Published by the American College of Nutrition 
$[10,11]$. Folate may work by influencing the cell cycle and apoptosis [12,13], but studies have not proven its role in cancer prevention. Similarly, epidemiological evidence points to a negative association between various food components and cancer, for example, lycopene with prostate, lung, and stomach cancers [14] and dietary fiber with colorectal cancer [15]. But, again, studies to date have not satisfactorily explained how these food constituents might prevent cancer.

Hesitance to accept epidemiological data without corroborating mechanisms may be compounded by inconclusive or patently disappointing results of human intervention trials. To illustrate, a meta-analysis of human intervention trials with folate has negatively associated folate intake with risk consistently for some cancers, such as colorectal, but not consistently for other cancers, such as cervical [13]. Trials with supplementary $\beta$-carotene have failed to demonstrate reduced risk of cancer but have, under certain conditions (in heavy smokers, alcohol drinkers and asbestos workers), shown an increased risk of cancer. And trials using three or four years of diets with increased amounts of various combinations of fruits, vegetables and grains - a fiber-enriched diet- have shown no effect on recurrence of colorectal adenoma [16,17].

But such seemingly negative evidence must be considered carefully. For instance, an increased cancer risk with $\beta$-carotene supplementation may be attributable to differences in the action of supplemental $\beta$-carotene versus a more natural balance of other carotenoids, antioxidants and phytochemicals $[18,19]$. Unexpected results of some fiber trials may be attributable to the general point that long-term diet is more important to complete prevention of cancer than short-term interventions are to repeated occurrence of precancerous lesions [20].

The point is that a paucity of "hard data" and ambiguous or seemingly contradictory results of intervention trials may foster reticence to fully embrace preventative nutrition, but such reticence is not justified. These issues do not unlink diet and cancer. Rather, they only reveal the nascent state of our knowledge about how foods influence cancer.

Temple [21], taking this general idea one step further, argues that a fundamental problem underlies both the desire to discover mechanisms of protection against cancer and the failure of intervention trials to prevent cancer. That is, there may be no "magic bullet," no standalone substance extractable from food. Rather, various anticarcinogenic vitamins, phytochemicals and the like may exert their benefit by acting as a "team." This team counters the action of such cancer-promoting agents as tobacco smoke and immoderate amounts of red meat. Progress will come from intervention trials employing the appropriate mixture of whole foods. It does not depend on discovering the mechanisms of action of anticarcinogenic vitamins and phytochemicals.

Clearly, therefore, there are still many gaps in our understanding of the relationship between nutrition and cancer. Indeed, there have been numerous shifts over the years in our understanding of the dietary factors involved in the causation and prevention of cancer. These shifts, not surprisingly, may have led to reluctance in many quarters to take forceful action.

\section{STRATEGIES TO PREVENT CANCER}

Despite these problems we do have hard evidence that much cancer can be prevented by diet, especially by a generous intake of fruit and vegetables. Unfortunately, these foods are consumed in conspicuously low amounts by large numbers of both adults and children in industrialized countries [22,23]. If it is so well established that diet and cancer are related, why have we not changed (or, at best, only marginally changed) the Western diet at individual and societal levels [24]? This question can be explored from several perspectives. The focus here is limited to preventing cancer through individual counseling by primarycare physicians, public education campaigns and determined government policy.

\section{Nutrition and Primary-Care Physicians}

To change diet by appealing to individuals, it would seem that primary-care physicians are potentially excellent instruments. However, several obstacles thwart basic preventative nutrition counseling in the physician's office. One is the incomplete state of our understanding of the subject, as discussed above. Others are lack of time and expectations of noncompliance [25].

One noteworthy obstacle in the United States is that medical insurers tend to pay readily for reactive procedures (e.g., surgery for cancer), yet balk at paying for most preventative measures [4,25]. Another, perhaps more fundamental, obstacle is that medical training leaves most physicians poorly educated in nutrition [26]. These last two obstacles are related. They are underlain by priorities that value reactive more than proactive methods. Physicians may, for instance, place great importance on self-examination in detecting early breast cancer, yet little importance on nutrition in preventing various future cancers $[25,27]$. Not surprisingly, standard medical textbooks commonly acknowledge data linking diet with cancers, yet diminish the importance of this information with conclusions to the effect that "there is no definite proof that diet can cause or protect against cancer" [27].

\section{The Limits of Health Promotion}

Realigning medical priorities to reflect the importance of preventative nutrition, important though this is, cannot solve the whole problem. Even if inertia in medical models can be overcome so that preventative nutrition is given its well deserved priority, evidence indicates that individual counseling in a health-care setting has only limited potential to change behavior $[25,28]$. It seems, then, that bringing preventative nutrition fully to the vanguard will require a more wide-ranging strategy. 
Several approaches aimed at changing dietary habits have already been tried or are in place around the world in the form of public education campaigns, cancer awareness initiatives, prevention-focused internet sites and so forth [29]. In Canada [30,31] and the United States [32], for instance, health and nutrition have been given much attention by government in recent decades. Manifestations of this in both countries include ongoing national health agendas, health recommendations and related grassroots initiatives.

Despite such attention, health promotion has met with only limited success. Many recent efforts-such as internet information sites and many small-scale community initiativesremain to be fully evaluated, but large-scale community intervention projects and interventions in the workplace have typically produced only modest trends toward a healthier lifestyle $[28,30]$. In particular, change in the Western diet achieved through health promotion has so far been mediocre [22,24,25,28,32].

Why have our efforts been so undramatic? Mediocre change may reflect insipid or poorly aimed applications of potentially much more effective public health marketing methods. For example, one of the most effective agents in public health marketing - as anyone exposed to television might expect-is paid advertising [28,33]. Yet, in the United States, as has been pointed out by several researchers, advertising dollars spent by the comestibles industry (e.g., McDonald's, Coca Cola) loom ridiculously large in comparison to education dollars spent by health promotion agencies (e.g., the National Cancer Institute) [33].

We have amassed much information indicating that children should be targeted in health promotion campaigns [22]. Studies have shown that counseling parents about nutrition, offering a variety of healthy foods and manipulating a host of other factors can affect children's food choices. For example, easier availability leads to greater consumption of particular foods, while higher socioeconomic status of parents is associated with a more nutritious diet [34,35]. As such, not only educating parents and children, but also otherwise influencing children's eating habits (by methods that will be discussed shortly) may represent our best opportunities to change the course of cancer. Accordingly, they should become major priorities.

\section{Government Policy: The Key to an Integrated Approach}

Individual counseling in a health-care setting and public health promotion have roles in bringing preventative nutrition to the vanguard, but, as noted above, those methods, at least as presently implemented, suffer from limited effectiveness. We can summarize the problem in the words: "You can lead a horse to water, but you can't make it wear a swimsuit." Behavior, including eating patterns, reflects a lifetime of conditioning. It is strongly influenced by such factors as cultural norms, socioeconomic status and advertising. These factors, predictably, are resistant to health promotion campaigns. Accordingly, more effective methods are required. This points to the necessity for governments to take action to remove barriers to healthy choices. As an example of public health policies, Nestle and Jacobson [33] proposed a range of policies designed to reduce the prevalence of obesity.

Such a strategy for cancer prevention could include action designed to shift the national diet (e.g., legislating against certain types of advertising, restricting grocery store promotional "freebies" to healthful foods, replacing school pop machines with fruit and vegetable bowls) [33,36,37]. And it could go further. The most effective actions will probably be economic, involving subsidies and taxation. Studies show that sales of tobacco and alcohol vary negatively with price [3840], and that fruit and vegetable consumption levels increase with decreasing price $[37,41,42]$. This strategy was suggested in the 1988 World Health Organization imperative that: "Taxation and subsidies should discriminate in favor of easy access for all to healthy food and improved diet" [36]. In other words governments should explore taxing nonnutritious items while subsidizing fruit, vegetables and whole grains.

\section{CONCLUSIONS}

This paper has discussed the general point that progress in finding out how to prevent cancer has been much more rapid than progress in finding out how to cure the disease. Details remain to be worked out, but with respect to gross dietary considerations, there exists sufficient evidence on which to act.

Yet the "war" on cancer is still dominated by early detection and therapy rather than by prevention. Certainly, treatment of extant cancer is extremely important for suffering individuals, but a nearly exclusive focus on treatment represents a gross misdirection of resources. Even if clinical trials of new cancer treatments prove highly successful, primary prevention will remain paramount. Health-care professionals should confidently promulgate a cancer-preventing diet that avoids known risk factors and includes abundant fruits, vegetables and whole grains.

Health promotion campaigns - both in the community and at the worksite-can also be advocated. These approaches, however, have limited effectiveness. On their own, they are unlikely to lead to major reductions in the burden of cancer and other Western diseases.

We must go beyond health promotion and develop a strategy based on government policies. Such public health policies will extend to the school, the supermarket and the airwaves. By means of taxation and subsidies, people will be encouraged to lead a healthier lifestyle, much as is already done with tobacco and alcohol. The new philosophy is based on removing barriers 
to a healthier lifestyle. To the extent that cancers can be prevented, we must ensure that they are.

\section{Norman J. Temple, PhD \\ Audrey L. Balay-Karperien, BS}

Centre for Science

Athabasca University

Athabasca, CANADA

E-mail: normant@athabascau.ca

\section{REFERENCES}

1. Temple NJ, Burkitt DP: The war on cancer—failure of therapy and research: discussion paper. J Roy Soc Med 84:95-98, 1991.

2. Bailar JC, Gornik HL: Cancer undefeated. N Eng J Med 336:15691574, 1997.

3. Welch HG, Schwartz LM, Woloshin S: Are increasing 5-year survival rates evidence of success against cancer? JAMA 283: 2975-2978, 2000.

4. World Cancer Research Fund (ed): "Food, Nutrition and the Prevention of Cancer: a Global Perspective." Washington, D.C.: American Institute for Cancer Research, 1997.

5. Greenwald P, McDonald SS: Antioxidants and the prevention of cancer. In Basu TK, Temple NJ, Garg ML (eds): “Antioxidants in Human Health and Disease." Wallingford, Oxon, UK: CABI Publishing, pp 217-234, 1999.

6. Clifford CK, McDonald SS: Proper nutritional habits for reducing the risk of cancer. In Wilson T, Temple NJ (eds): "Nutritional Health: Strategies for Disease Prevention.” Totowa, NJ: Humana, pp 59-74, 2001.

7. Jacobs DR, Marquart L, Slavin J, Kuchi LH: Whole-grain intake and cancer: an expanded review and meta-analysis. Nutr Cancer 30:85-96, 1998.

8. Chatenoud L, Tavani A, La Vecchia C, Jacobs DR, Negri E: Whole grain food intake and cancer risk. Int J Cancer 77:24-28, 1998.

9. Steinmetz KA, Potter JD: Vegetables, fruit, and cancer prevention: a review. J Am Diet Assoc 96:1027-1039, 1996.

10. Davis CD, Feng Y, Hein DW, Finley JW: The chemical form of selenium influences 3,2'-dimethyl-4-aminobiphenyl-DNA adduct formation in rat colon. J Nutr 129:63-69, 1999.

11. Vinson JA, Stella JM, Flanagan RJ: Selenium yeast is an effective in vitro and in vivo antioxidant and hypolipemic agent in normal hamsters. Nutr Res 18:735-742, 1998.

12. Kim Y-I: Folate and carcinogenesis: evidence, mechanisms, and implications. J Nutr Biochem 10:66-88, 1999.

13. Huang R-FS, Ho Y-H, Lin H-L, Wei J-S, Liu T-Z: Folate deficiency induces a cell cycle-specific apoptosis in HepG2 cells. J Nutr 129:25-31, 1999.

14. Giovannucci E: Tomatoes, tomato-based products, lycopene, and cancer: review of the epidemiological literature. J Natl Cancer Inst 91:317-332, 1999.

15. Trock B, Lanza E, Greenwald P: Dietary fiber, vegetables, and colon cancer: critical review and meta-analyses of the epidemiologic evidence. J Natl Cancer Inst 82:650-661, 1990.
16. Alberts DS, Martinez ME, Roe DJ, Guillen-Rodriguez JM, Marshall JR, van Leeuwen JB, Reid ME, Ritenbaugh C, Vargas PA, Bhattacharyya AB, Earnest DL, Sampliner RE: Lack of effect of a high-fiber cereal supplement on the recurrence of colorectal adenomas. N Engl J Med 342:1156-1162, 2000.

17. Schatzkin A, Lanza E, Corle D, Lance P, Iber F, Caan B, Shike M, Weissfeld J, Burt R, Cooper MR, Kikendall JW, Cahill J: Lack of effect of a low-fat, high-fiber diet on the recurrence of colorectal adenomas. N Engl J Med 342:1149-1155, 2000.

18. Knekt P, Jarvinen R, Teppo L, Aromaa A, Seppanen R: Role of various carotenoids in lung cancer prevention. J Natl Cancer Inst 91:182-184, 1999.

19. Onogi N, Okuno M, Matsushima-Nishiwaki R, Fukutomi Y, Moriwaki H, Muto Y, Kojima S: Antiproloferative effect of carotenoids on human colon cells without conversion to retinoic acid. Nutr Cancer 32:20-24, 1998.

20. Byers T: Diet, colorectal adenomas, and colorectal cancer. N Engl J Med 342:1206-1207, 2000.

21. Temple NJ: Fruits, vegetables, and cancer prevention trials. J Natl Cancer Inst 91:1164, 1999.

22. World Health Organization Regional Office for Europe: "Health and Health Behaviour among Young People: Health Behaviour in School-aged Children." WHO Policy Series: Health policy for children and adolescents (international report) 1:84-96, 2000.

23. Patterson BH, Harlan LC, Block G, Kahle L: Food choices of whites, blacks, and Hispanics: data from the 1987 national health interview survey. Nutr Cancer 23:105-119, 1995.

24. U.S. Department of Health and Human Services: "Nutrition Progress Review. Healthy People 2000: Progress Reviews." Washington, DC: DHHS, 1998.

25. U.S. Department of Health and Human Services: "Access to Quality Health Services. Healthy People 2010,” vol 1 (conf ed, 2 vols). Washington, DC: DHHS, 2000.

26. Temple NJ: Survey of nutrition knowledge of Canadian physicians. J Am Coll Nutr 18:26-29, 1999.

27. Kane AB, Kumar V: "Environmental and Nutritional Pathology: Robbins Pathologic Basis of Disease." Philadelphia: Saunders, 1999.

28. Temple NJ, Nestle M: Population nutrition, health promotion and government policy. In Wilson T, Temple NJ (eds): "Nutritional Health: Strategies for Disease Prevention.” Totowa, NJ: Humana, pp 13-29, 2001.

29. National Center for Chronic Disease Prevention and Health Promotion: "Cancer Prevention and Control." Centers for Disease Control and Prevention: http://www.cdc.gov/cancer/colorctl/ index.htm, visited February 2002.

30. Health Canada: "Health Promotion in Canada: a Case Study." Ottawa, ON: Supply and Services Canada, 1997.

31. Health Canada: "Health Infoway Canada: Paths to Better Health. Final Report of the Advisory Council on Health Infostructure." Ottawa, ON: Minister of Public Works and Government Services, 1999.

32. U.S. Department of Health and Human Services: "Nutrition and Overweight. Healthy People 2010," vol 2 (conf ed, 2 vols). Washington, DC: HHS, 2000.

33. Nestle M, Jacobson M: Halting the obesity epidemic: a public health policy approach. Public Health Rep 115:12-24, 2000.

34. Simell O, Niinikoski H, Viikari J, Rask-Nissilä L, Tammi A, 
Tapani R: Cardiovascular disease risk factors in young children in the STRIP baby project. Ann Med 31:55-61, 1999.

35. Hursti U-K: Factors influencing children's food choice. Ann Med 31:26-32, 1999.

36. World Health Organization Regional Office for Europe: "The Adelaide Recommendations: Healthy Public Policy." Geneva: WHO, 1988.

37. French SA, Story M, Jeffery RW, Snyder P, Eisenberg M, Sidebottom A, Murray D: Pricing Strategy to promote fruit and vegetable purchase in high school cafeterias. J Am Diet Assoc 97: 1008-1010, 1997.

38. Meier KJ, Licari MJ: The effect of cigarette taxes on cigarette consumption, 1955 through 1994. Am J Public Health 87:11261130, 1997.
39. Townsend J: Price and consumption of tobacco. Br Med Bull 52:132-142, 1996.

40. Anderson P, Lehto G: Prevention police. Br Med Bull 50:171-185, 1994.

41. Jeffery RW, French SA, Raether C, Baxter JE: An environmental intervention to increase fruit and salad purchases in a cafeteria. Prev Med 23:788-792, 1994.

42. French SA, Jeffery RW, Story M, Hannan P, Snyder P: A pricing strategy to promote low-fat snack choices through vending machines. Am J Public Health 87:849-851, 1997.

Received January 29, 2001; revision accepted August 8, 2001. 